\title{
Editorial
}

\section{Current nursing practice: challenges and successes}

The changing healthcare environment is placing greater demands on all healthcare service sectors, including nursing practice. Nurses are professionally engaged in caring for human beings and to pursue nursing as their profession actively (Merriam Webster Dictionary 2011). However, every year, changes in the healthcare environment accelerate, opportunities become harder to predict, competitors emerge at an ever-increasing pace and partnering with internal and external customers becomes essential for success. It is thus inevitable that the pace of changes in nursing practice will continue to increase, and the level of complexity and interdependence in practice will continue to grow (Boss \& Sims 2008, Politis 2006). These new practices and the things nurses will focus on will become their reality, and the actions they will perform will create their reality (Hall \& Hammond, Reed 2007).

Nursing is a regulated profession that forms an integral part of a comprehensive healthcare system practised, by persons registered or licenced under a nursing act. Nursing practice entails a dynamic process based on scientific knowledge, skills and judgment within a caring environment that maintains continuity and coordination of healthcare. Through publications such as the Journal of Nursing Management we share our scientific findings. Nurses have always been accountable to their clients for the quality and character of their practice and to society for safe and competent practice through licensure laws. However, it is no longer enough to just follow a correct procedure or process. Nurses uncover and use research-based knowledge as the foundation for evidence-based practice to be accountable for effectiveness in service delivery (Jooste 2010).

The scope of practice is the activities that a professional nurse performs in the delivery of client care. It includes responsibilities and accountability in practice issues. However, four different factors affecting current nursing practices, should be mentioned. The first factor is financially related. The pressure to achieve better expenditure control, greater productivity and efficiency challenges the moral imperatives in healthcare services, which are to maintain access to the necessary healthcare services and to ensure an equitable distribution of healthcare resources.

The above mentioned are some challenges for nurses and nurse managers in nursing practice that require a new mindset in terms of thinking about, perceiving and understanding the changing nursing practice environment. The ideal nursing situation could be viewed, where research findings are implemented in nursing practice to contribute to the development of practice.

Practice development has been taken up by many organizations as a way of focusing on nurses' practices to benefit patients and the organization. McCormack et al. (2004) defines practice development as a continuous process of improvement toward increased effectiveness in patient centred care. However, Rudge et al. are in their article, of the opinion that nursing managers should understand that practice development (PD) is not a final solution for improving patient care. It is argued that while PD is portrayed as transforming practice, nurses bear the responsibility for the system and its failures within a reformed bureaucracy.

In this issue of the Journal of Nursing Management, practice issues refer to caring, individualized care, patient centred care, evidence-based practice, health promotion and making use of technologies and forensics in the nursing practice fields of home-based care, the elderly, advanced practice nursing, medical units, midwifery, child care and mental health.

Nursing practice is characteristic of new technologies. Terminologies such as nursing informatics and tele- nursing are common in nursing today (McNeil et al. 2006). Previously, one would only have thought of high technology units, however medical technology has, in recent years, also been widely used in palliative home- care. In the article of Munck et al., it is highlighted that nursing staff need regular training on medical devices and must be more specialized to handle this new technology, kind of care. On the positive side, medical technology provided freedom for palliative patients, however it is a demanding task. It demands changing tasks, self-reliance and an awareness of managing medical technology in a patient-safe way. To maintain patient safety, it is recommended that more collaboration with palliative care teams and next-of-kin takes place. Next-of-kin are considered as an important resource but their participation must be based on their own conditions. 
Another interesting technological breakthrough is the use of a personal digital assistant in nursing practice. An interesting single case study is presented by the authors Johansson, Pettersson and Nilsson on experiences of using a personal digital assistant (PDA) in nursing practice. The incorporation of a multifunctional PDA is an important issue for nursing management, as it could both change and provide new possibilities for nursing practice. As pointed out by the authors, the use of PDAs could also aid decision-making, improve patient safety and benefit patient outcomes. It is therefore essential to effectively manage the implementation of new health care technology to realize the desired benefits. The results of a study reported in the article of Miller et al. indicate significant differences in night- and dayshift nurses' perceptions of technology benefits. This could be a barrier in the implementation of continuous patient monitoring in e.g. acute post-surgical nursing units. Effective approaches for managing barriers to new technology implementation are thus needed. Exploratory action-feedback approaches can assist nurse managers in assessing and mitigating the real-world effects of health information technology (HIT) implementations.

Nurse managers should also identify stakeholders and develop comprehensive plans for monitoring the effects of HIT in their units. Nkosi et al. in their article titled 'Post-basic nursing students' access to and attitudes toward the use of information technology in practice: a descriptive analysis', state that the effect of the integration of Information Technology (IT) in healthcare systems is the provision of quality of care.

As previously mentioned, we currently have an aging population. The aging population is two folded referring to the aging population in the community and the aging population of nurses. Firstly, there is a need to examine the care structures and processes and the role of nurse professionals in older people's care under the guidance of nurse leaders and managers. The authors Suhonen et al. state in their article about the individuality in older people's care, that individualized care is enshrined in health-care policies and ethical and quality guidelines. They reveal shortcomings in the maintenance of individuality in older people's care. Nurses need to change the focus of care from reactive management to a proactive prevention orientation to improve the well- being of older people. Secondly, we are having a situation of an aging population of nurses. In some countries such as South Africa, the Minister of Health is requesting retired nurses to return to the profession. What rewards and inspires a nurse to continue to work beyond retirement age, and to act as a seasoned nurse in active practice? In their article, authors Friedrich et al. spell out that nurse managers should understand the pre-existing attitudes, important needs and unique contributions of a seasoned nurse to retain them in practice. Seasoned nurses should be able to enjoy and engage in nursing and derive benefits from continued practice.

From the discussion on practice issues, it is evident that nurses are an important resource in the development of evidence-based nursing and to improve the availability of adequate health and nursing-care services for patients. The article of Nilsson et al. states that nurses also need support structures. Workplace health promotion activities are improvements for creating a healthy workplace (Whitehead 2006), which could contribute to enhancing health and well-being from a physical, psychological and social point of view (Aker- lind et al. 2007). The psychological empowerment of registered nurses could lead to an experience of job satisfaction and also quality patient care (Engstrom et al. 2009). The article of Myburg et al. argues that ward managers can facilitate the psychological empowerment of registered nurses by facilitating their self-awareness, managing disturbances in behaviour, and facilitating security measures in medical wards. Further support measures are outlined by the article of Fagerstrom and Glassberg which states that nurse leaders are responsible for creating sustainable structures and the prerequisites needed for advanced practice nursing, through the formation of supportive organizational systems.

Much has been written on advanced practitioners. Internationally, advanced practice posts have often developed in an ad-hoc manner, with little organizational attention to succession planning. Succession planning is a business concept focused on systematically identifying and preparing individuals to take up key roles in an organisation when they become available 
(Carriere et al. 2009). In an article, related to 'Building Foundations for the Future...', the authors state that the roles of advanced nurses need to be sustainable and linked to areas of service needs, and that achieving this requires effective succession planning mechanisms (Currie et al. 2010). In the article of authors Barton and Mashlan, an advanced nurse practitioner team is de-scribed, working in collaboration with Medical Consultants. This was a model for future service redesign in an acute hospital setting that presented challenges to senior healthcare managers on organisational infra-structures. Assistance to address the challenges of advanced roles are available that offers guidance to employers, practitioners and educators. Most recently there has been the Nursing and Midwifery Councils (NMC) deliberations on advanced nursing practice, the publication of the All Wales Guidelines for Advanced Nursing Practice (NLIAH 2010), and the publication of the Department of Health (DoH 2010) position state-ment on Advanced Nursing Practice.

On the other hand, advanced practitioners in, for example, psychiatric units also have their challenges. According to the annual report (UNESCO, 2005) youths from different countries agreed that crime and violence are facilitated by the easy availability of guns and ammunition. Daily, one reads in the newspapers about crime and hostile behaviours. In one incident, the victim was told by the police officers 'the crimes are happening so often that we can't keep up' (Ajam \& Bailey 2009). Myburg et al. in the background of their article, describe that hostility prevails at all settings, including in the health sector, and that in a forensic ward, psychiatric nurses could be subjected to hostile behaviour by the patients. However, nurse managers can facilitate psychiatric nurses' empowerment by pro-viding them access to: information, support, resources, opportunity and growth.

Van Rensburg and Human write about 'Challenges in the management of support and care programmes for child-headed households in South Africa.' Their article states that the complexity of the phenomenon necessitates effective scientific management principles. Due to the rapid rates at which orphan hood and destitution are currently occurring, families and communities find it difficult or are not willing to respond to supporting and caring for orphaned children (Bequele 2007). Thus positive outcomes could be achieved by providing legal clarity of the concept; relevant policies and effective implementation; rigorous monitoring and evaluation based on comprehensive empirical data; protecting the rights and safety of these children and ensuring an enabling environment for all stakeholders to address needs and challenges.

Van Niekerk et al. write a paper that focuses on the implications for nurse managers to support midwives in delivering nursing care to immigrant mothers in some government hospitals in South Africa. At any given time, there are 13 million refugees and asylum seekers worldwide (Kitzinger 2005). The findings in the mentioned article of Van Niekerk et al. indicate that nurse managers should ensure actions in combating issues related to impaired maternal-midwife relationship, lack of cultural sensitivity and psychological distress. 


\section{References}

Ajam K. \& Bailey C. (2009) Gang pistol-whips top lawyer and family. Saturday Star, 7 February, 3.

Akerlind I., Schunder S. \& Frick K. (2007) Health and work organization. In Work Health and Management Control (U. Johanson, G. Ahonen \& R. Roslender eds), pp. 3-21, Thomson Fakta, Stockholm.

Benner M.J. \& Tushman M.L. (2003) Exploitation, exploration and process management. Academy of Management Review 28 (2), 238-256.

Bequele A. (2007) The Emerging Challenges of Children Heading Households: Some Reflections, The African Child Policy Forum, Addis Ababa, Ethiopia.

Carriere B. K., Muise M., Cummings G. \& Newburn-Cook C. (2009) Healthcare succession planning: an integrative review. Journal of Nursing Administration 39 (12), 548-555.

Currie K., Palmer J., Biggam J., Cochrane D. \& Lindsay G. (2010) Evaluation of the NHS Education for Scotland Advanced Practice Succession Planning Development Pathway. Final Report. NHS Education for Scotland, Edinburgh.ISBN9781905866489.vailableat:http://www.nes.scot.nhs.uk/media/398479/full-final-report-evalu ation-of-apspdp.pdf, accessed 25 May 2011.

Department of Health (2010) Position statement on Advanced Practice. HMSO, London.

Engstrom M., Wadensten B. \& Haggstrom E. (2009) Caregivers' job satisfaction and empowerment before and after an inter $\neg$ vention focused on caregiver empowerment. Journal of Nursing Management, 18, 14-23.

Hall J. \& Hammond S.A. (2004) What is Appreciative Inquiry? Thin book Publishing Co., New York.

Jooste K. (2010) Principles and Practice of Nursing and Health Care.Van Schaiks, Pretoria.

Kitzinger S. (2005) The Politics of Birth. Elsevier Butterworth Heinemann, London.

McCormack B., Manley K. \& Garbett R. (2004) Practice Development in Nursing. Blackwill Publishers, Oxford.

McNeil B., Elfrink V., Beyea S., Pierce S. \& Bickford C. (2006) Computer literacy study: report of qualitative findings. Journal of Professional Nursing 22 (1), 52-59.

Merriam Webster Dictionary (2011). Available at: http://www. merriam-webster.com/dictionary/practice, accessed 8 August 2011.

National Leadership and Innovation Agency for Health Care (2010) All Wales guidelines for advanced practice. Available at: http://www.wales.nhs.uk/, accessed 01 August 2011.

Reed J. (2007) Appreciative Inquiry: Research for Change. Sage Publications, USA.

UNESCO (2005) Report of the UNESCO general conference youth forum. 33rd General Conference, 30 September- 2 October 2005. Paris.

Whitehead D. (2006) Workplace health promotion: the role and responsibility of health-care managers. Journal of Nursing Management 14, 59-69. 